\title{
Kaposi's sarcoma a series of cases and review of the literature
}

\begin{abstract}
Introduction: Kaposi's sarcoma is a neoplasm associated with the Human Immunodeficiency Virus (HIV) - AIDS especially in advanced stages, in Quintana Roo HIV-AIDS ranks first in the country.
\end{abstract}

Methodology: A series of 22 cases with diagnosis confirmed by biopsy attended by the oncology service of HGR No. 17 is presented.

Results: They were classified as low risk (4); three of them with complete response. High risk (18); fifteen accepted chemotherapy. Nine (60\%) received liposomal doxorubicin and six $(40 \%)$ paclitaxel; of these, four had a complete response, one partial response, six with stable disease and five with disease progression that required a second line. The presence of adverse effects associated with chemotherapy treatment was documented in six patients classified as high risk (40\%).

Conclusions: Clinical interventions with therapeutic trials are necessary, since the available evidence dates from periods of more than 10 years ago. HIV patients require continuous monitoring and clinical trials to improve the therapeutic options available to treat one of the most common oncological diseases in this population such as Kaposi's Sarcoma.

Keywords: kaposi, HIV, AIDS, liposomal doxorubicin, paclitaxe
Volume II Issue 4 - 202 I

\author{
Naranjo Cruz Alondra Yeraldi,' Hernández \\ Hoil Lorena Berenice, ${ }^{2}$ Chávez Hernández \\ María Margarita, ${ }^{3}$ Jiménez-Baéz María Valeria ${ }^{4}$ \\ 'Medical oncologist, Regional General Hospital No. 17, Mexican \\ Social Security Institute, Mexico \\ ${ }^{2}$ Second Year Resident of Internal Medicine. Regional General \\ Hospital No. 17. Mexican Social Security Institute, Mexico \\ ${ }^{3}$ Endocrinologist, Assistant Medical Coordinator of Health \\ Education, Mexican Social Security Institute, Mexico \\ ${ }^{4}$ Medical Coordinator of Health Education, Mexican Social \\ Security Institute, Mexico
}

Correspondence: Maria Valeria Jiménez Báez, Medical Coordinator of Health Education, Mexican Social Security Institute, Mexico,Tel 9988742354 . Email Valeria.jimenezb@gmail.com

Received: July I5, 202I | Published: July 27, 2021

\section{Introduction}

Kaposi's sarcoma is a neoplasm induced by the Human Herpes Virus-8 (HHV8) first identified in 1994. Currently its relevance comes from its relationship with human immunodeficiency virus (HIV) infection in advanced stages.

In the United States, it is estimated that there is a population of 1.2 million people with HIV, of whom $14 \%$ are unaware of the disease. ${ }^{1}$ In Mexico, at the end of 2019, a total of 210,931 cases of acquired immunodeficiency syndrome (AIDS) have been reported since 1983. ${ }^{2}$ The incidence in 2019 was 9,828 HIV patients of which 5,825 debuted as AIDS. Currently, Quintana Roo is in the second place of incidence in AIDS and first place in HIV. Its mortality rate stands at 3.82 per 100,000 population. The average age is $25-34$ years. $^{3}$

Among the oncological diseases defining AIDS are non-Hodgkin lymphoma, Kaposi's sarcoma (SK) and cervical carcinoma ${ }^{4}$ with Kaposi's sarcoma being the 2rd place in incidence. ${ }^{5}$ Globally, Kaposi's sarcoma ranks thirty-one in cancer incidence and mortality in 2020, with a prevalence in Africa of $71 \%$ followed by Europe and Latin America with $8.8 \%$ and $8.3 \%$ respectively. ${ }^{6}$

Kaposi's sarcoma is an angioproliferative tumor that originates from human Herpes Virus 8 (HHV8) infection into the endothelium cell and maintains cellular replication. It normally involves the skin, oral cavity and gastrointestinal tract but can also involve distant tissues such as lungs, lymphatic system and liver. ${ }^{7}$ The lesions are usually pink, red or purple that do not pale to pressure and asymptomatic, however, they can become exophytic and ulcerated associated with painful edema. ${ }^{8}$ Although the lesions are usually characteristic, the diagnosis must be confirmed histologically. ${ }^{4}$

There are 4 epidemiological variants. The AIDS-associated or epidemic is the most aggressive and the most common in the West and Africa which can progress despite the control of HIV infection and autoimmune reconstitution. The other forms include classic Kaposi's sarcoma being an indolent disease in the elderly from the Mediterranean; Endemic Kaposi sarcoma in Africa that occurs in children and young adults; and iatrogenic Kaposi sarcoma that occurs mostly in transplant patients. ${ }^{4}$

The low incidence of this pathology globally limits adequate research and sample sizes. In Quintana Roo we observed a high incidence of cases due to the high prevalence of population with HIV so the purpose of this article is to present a series of cases from a second level of care hospital, their evolution with treatment and literature review.

\section{Case description}

We present 22 cases attended in the medical oncology outpatient clinic of HGR No. 17 Cancun, Quintana Roo from January 2016 to November 2020. Table 1 shows the clinical characteristics. The majority were male $(90.9 \%)$ with a mean age of 32 years and an average time of HIV diagnosis of less than a year. The mean CD4 cell count during the first consultation was $141 \mathrm{cel} / \mathrm{mm}^{3}$ of which six patients had CD4 above $200 \mathrm{cel} / \mathrm{mm}^{3}$. The mean follow-up was 30 months. 
Table I Shows the clinical characteristics

\begin{tabular}{|c|c|c|c|}
\hline \multicolumn{2}{|c|}{ Table I. Patients's features } & \multirow{2}{*}{$\begin{array}{l}\text { Percentage } \\
90.9 \%\end{array}$} & \multirow{2}{*}{$\begin{array}{l}\mathbf{n} \\
20\end{array}$} \\
\hline Sey & Male & & \\
\hline sex & Female & $9.1 \%$ & 2 \\
\hline \multirow{3}{*}{ Age } & $18-25$ years & $9 \%$ & 2 \\
\hline & $26-35$ years & $63.6 \%$ & 14 \\
\hline & More than 35 years & $27.4 \%$ & 6 \\
\hline \multirow{2}{*}{ TIS Stage } & Low Risk & $18.2 \%$ & 4 \\
\hline & High Risk & $81.8 \%$ & 18 \\
\hline \multirow{6}{*}{ Disease location } & Face & $31.8 \%$ & 7 \\
\hline & Limbs & $13.6 \%$ & 3 \\
\hline & Disseminated & $9 \%$ & 2 \\
\hline & Thorax & $9 \%$ & 2 \\
\hline & Mucous & $31.8 \%$ & 7 \\
\hline & Gastroesophageal & $4.5 \%$ & I \\
\hline \multirow{5}{*}{ Antirretroviral } & Bictarvy & $9 \%$ & 2 \\
\hline & Lopinavir/Ritonavir + Truvada & $13.6 \%$ & 3 \\
\hline & Stribild & $9 \%$ & 2 \\
\hline & Ritonavir Arazanavir + Truvada & $27.2 \%$ & $\begin{array}{l}2 \\
6\end{array}$ \\
\hline & Efavifenz+ Truvada & $40.9 \%$ & 9 \\
\hline \multirow{4}{*}{ CD4+ } & $\leq 100 \mathrm{cel} / \mathrm{mm} 3$ & $36.3 \%$ & 8 \\
\hline & $101-200 \mathrm{cel} / \mathrm{mm} 3$ & $36.3 \%$ & 8 \\
\hline & $20 \mathrm{I}-300 \mathrm{cel} / \mathrm{mm} 3$ & $13.6 \%$ & 3 \\
\hline & Más $300 \mathrm{cel} / \mathrm{mm} 3$ & $13.6 \%$ & 3 \\
\hline \multirow{4}{*}{ Viral load } & $\leq 50$ copies $/ \mathrm{ml}$ & $18.1 \%$ & 4 \\
\hline & 50-500 copies/ml & $36.3 \%$ & 8 \\
\hline & 500-I000 copies/ml & $40.9 \%$ & 9 \\
\hline & $\geq 1000$ copies $/ \mathrm{ml}$ & $4.5 \%$ & 1 \\
\hline \multirow{2}{*}{$\begin{array}{l}\text { First line treatment } \\
(n=\mid 5)\end{array}$} & Liposomal doxorubicin & $60 \%$ & 9 \\
\hline & Paclitaxel & $40 \%$ & 6 \\
\hline \multirow{3}{*}{ Number of cycles } & 5 or less & $26.6 \%$ & 4 \\
\hline & 6 to 8 & $66.6 \%$ & 10 \\
\hline & 9 or more & $6.6 \%$ & I \\
\hline \multirow{2}{*}{$\begin{array}{l}\text { Second line } \\
\text { treatment } \\
(n=4)\end{array}$} & Liposomal doxorubicin & $25 \%$ & I \\
\hline & Paclitaxel & $75 \%$ & 3 \\
\hline \multirow{3}{*}{ Number of cycles } & 5 or less & $0 \%$ & 0 \\
\hline & 6 a 8 & $33.3 \%$ & I \\
\hline & 9 or more & $66.6 \%$ & 2 \\
\hline \multirow{2}{*}{ Complications } & Anemia & $20 \%$ & 3 \\
\hline & Neutropenia & $20 \%$ & 3 \\
\hline
\end{tabular}

Four patients $(18 \%)$ were classified as low-risk Kaposi's sarcoma so they did not require systemic treatment and only active surveillance was performed along with the use of antiretrovirals achieving partial $(20 \%)$ and complete $(80 \%)$ response during this period.

Among those classified as high risk $(\mathrm{n}=18 ; 81.8 \%)$, one of them had esophageal and gastric involvement. Among these patients, fifteen $(83.3 \%)$ agreed to start chemotherapy. All were users of antiretroviral drugs at the start of treatment, most were using efavirenz+emtricitabine/tenofovir $(40 \%)$; Nine $(60 \%)$ started with liposomal doxorubicin and six with paclitaxel (40\%). The response was evaluated by ACTG criteria. Of the 9 who started doxorubicin, two $(22 \%)$ had a complete response, one partial response, three stable disease (33\%) and four progression (44\%). Those with disease progression were initiated with paclitaxel as second line of treatment of which three had partial response $(75 \%)$ and one stable disease. In the case of initiation of treatment with paclitaxel, two patients achieved complete response (33\%), three stable disease (50\%) and one required second-line management with liposomal doxorubicin maintaining a partial response $(16 \%)$. None of the patients required a third line of treatment.

Among the adverse effects, the presence of anemia was documented in three $(50 \%)$ patients with the use of paclitaxel without requiring blood transfusion and three (33\%) with neutropenia in those who used liposomal doxorubicin, of which 2 required the use of filgastrim.

In total, among patients with high-risk Kaposi sarcoma who initiated systemic therapy, four had complete response $(26 \%)$, one partial response, six stable disease $(40 \%)$ and five disease progression $(33 \%)$ which required a second line. The presence of adverse effects associated with systemic treatment was documented in six patients $(40 \%)$. 


\section{Discussion}

Kaposi's sarcoma is diagnosed by biopsy of the affected lesion or lymph nodes showing angioproliferative features combined with spindle cells and abnormal vessels with inflammatory infiltrate. ${ }^{4}$ Immunohistochemistry (IHC) is positive for KSHV (HHV8) and LANA-1. The IHC that is useful in a diagnostic way in some circumstances is CD31 and CD34 in cases where it is uncertain if it is a tumor of vascular origin. ${ }^{4}$

To date, kaposi sarcoma staging has not been incorporated into the Tumor-Nodule-Metastasis (TNM) staging system of the American Joint Committee on Cancer (AJCC) so the AIDS Clinical Trials Group (ACTG) classification is used, which is based on Tumor, Immune Status and Systemic Disease (TIS) ${ }^{8}$ It is classified as limited or lowrisk skin disease and advanced, visceral, ganglion or high-risk skin disease. $^{9}$

Recent studies have shown that immunity (I) has less prognostic value than the extent of the tumor (T) or if the disease is systemic (S) in the presence of antiretroviral use..$^{10} \mathrm{~A}$ T1S1 Kaposi sarcoma has the worst prognosis in a cohort of 211 patients where it was found that a Kaposi sarcoma classified as T1S1 had a 3-year survival of 53\% while the ones classified as T0S0, T1S0 or T0S0 was $88 \%, 80 \%$ and $81 \%$ respectively $(\mathrm{p}=0.0001){ }^{10}$

The treatment depends on the extent of the disease according to TIS, if it is classified as low risk or limited antiretroviral treatment (ART) and observation of the lesions is recommended in a clinical and radiographic way ${ }^{11}$ where it is documented and only in case of producing symptoms can be considered topical or systemic treatment since in these patients the optimization of the immunological function allows to achieve remission or stable disease. ${ }^{12}$

The 5-year survival of patients with HIV-associated Kaposi sarcoma has improved in the post-retroviral era, from $12.1 \%$ in 1980 to $88 \%$ since $1995 .{ }^{13}$ At present, survival depends on the progression of the disease since if it is localized it has a survival rate of $82 \%$ while if it is metastatic it decreases to $38 \%{ }^{14}$

The initiation of antiretroviral therapy together with the presence of Kaposi's sarcoma has been associated with the appearance of inflammatory reconstitution syndrome in the first 3 to 6 months, where there is an exacerbation of the lesions, appearance or exacerbation of pulmonary opacities and lymphedema. ${ }^{8}$ The presence of pulmonary involvement of Kaposi's sarcoma is a risk factor and if thrombocytopenia is involved there's an increase in mortality during reconstitution syndrome at week 12 of follow-up. ${ }^{15}$ Due to the above, it is recommended to avoid steroids as they are associated with the progression of KS and the appearance of inflammatory reconstitution syndrome. ${ }^{16}$

The studies to define the treatment of the disease have been limited by the low number of cases documented worldwide so just two years ago the National Comprehensive Cancer Network (NCCN) published its first guide of diagnosis and treatment, where most of the studies conducted are Phase II or those that are Phase III have more than 10 years since their realization so the NCCN suggests participating in study protocols in development in case of failure or intolerance to the recommended treatments. ${ }^{12}$

The response to treatment is defined according to the ACTG wherein the complete response (CR) corresponds to the absence of detectable residual disease for 4 weeks, including edema associated with tumor. ${ }^{12}$
The partial response (PR) is defined as the lack of new mucocutaneous lesions, visceral involvement, appearance or worsening of edema by the tumor, all of the above associated with a decrease equal to or greater than $50 \%$ in the number of previous lesions for at least 4 weeks or complete flattening of at least $50 \%$ of the elevated lesions (nodules or plaques) or a decrease of $50 \%$ in the sum of the 5 larger diameter lesions. ${ }^{12}$

Progressive disease (PD) is one with an increase equal to or greater than $25 \%$ of pre-existing lesions and/or the appearance of new lesions or areas of disease and/or a change in the characteristics of the skin or mucosa. If the edema associated with the tumor or effusion appears or increases, it is considered to have progressed. Stable disease (SD) is one that does not meet PD or PR criteria. ${ }^{12}$

In those with symptomatically or cosmetically unacceptable lowrisk disease, topical treatments such as alitretinoin can be used where a phase III clinical trial with 134 patients received $0.1 \%$ alitretinoinvs placebo for 12 weeks with $37 \%$ vs. $7 \%$ treatment responses in the control group. ${ }^{17}$ The use of imiquimod has also been documented where a phase I/II clinical trial found a $47 \%$ response to treatment against placebo when using imiquimod 3 times a day for 24 weeks. ${ }^{18}$

Complete remission in low-risk patients with the use of antiretrovirals ranges from 20 to $80 \%$ and is more common in patients who have never used ART with limited disease who comply with HIV treatment. ${ }^{19}$ The regression mechanism is considered to be immunological and associated with the cellular cytotoxic effect that is restored with the treatment and that is focused on HHV8.$^{19}$ In our series of cases, the minority was classified as low risk in which conservative management was decided with active observation where their treatment and follow-up correlated with the literature since none required initiating systemic management and most achieved complete remission of the disease.

The use of antiretrovirals in cancer patients requiring chemotherapy has been studied due to concerns of decreased therapeutic efficacy or increased adverse effects. It is currently recommended to start the use of ART 7 days before the start of anticancer treatment or 7 days after in order to differentiate the origin of possible adverse effects of both treatments. ${ }^{20}$ Discontinuation of antiretroviral therapy should be avoided due to the risk of immunological compromise, so in case of drug interactions, the antiretroviral should be changed to one with fewer interactions with cancer treatment. ${ }^{20}$

Kaposi sarcoma classified as high risk or disseminated requires systemic treatment where the first line of management is liposomal doxorubicin or paclitaxel. ${ }^{12}$ In the case of liposomal doxorubicin, its effectiveness is documented in a phase III study with 258 patients where liposomal doxorubicin was compared with doxorubicin/ bleomycin/vincristine (ABV). The response to treatment was $45.9 \%$ vs $24.8 \%(\mathrm{p}=0.001)$. The mean failure to treatment was 4 months in both groups. ${ }^{21}$ Stewart S. et al. in their study of liposomal doxorubicin compared with bleomycin/vincristine in 241 patients found a response of $59 \%$ vs $23 \% .^{22}$

In the case of paclitaxel, in the phase III study conducted at Northwestern University in Chicago with 73 patients, they compared paclitaxel with liposomal doxorubicin. Statistically they were equivalent in response, mean survival of free progression and survival at 2 years, however there was an increase in adverse effects from grade 3 to 5 with paclitaxel ( $84 \%$ vs $66 \%$ ) and a lethality with pulmonary embolism. ${ }^{23}$ 
For all the above evidence, current guidelines suggest starting with doxorubicin due to fewer reported adverse effects, including the most recent meta-analysis by Gbabe et $\mathrm{al}^{24}$ which reports no difference between liposomal doxorubicin, liposomal daunorubicin and paclitaxel, however the studies analyzed are of moderate evidence level. Although our patients were seen before the publication of these guidelines, the treatment agrees with the literature that considers them the first two lines that have shown greater benefit, however a higher proportion of patients requiring a second line of treatment was observed in those with liposomal doxorubicin, which suggests better results in terms of controlling the disease with the use of paclitaxel. As for complications, our cases agree with a higher proportion in those who used paclitaxel so it would be worth following up promptly on the adverse effects of this drug.

In the case of failure or progression of the disease the current guidelines recommend starting a second line with paclitaxel or even repeating liposomal doxorubicin if the failure was after 3 months of response. ${ }^{25,26}$ In third line the recommended treatment is with pomalidomide, which is referred to in a 2016phase I/II clinical trial of patients with Kaposi sarcoma with and without HIV where most had already received systemic treatment for Kaposi. ${ }^{27}$ The pomalidomide response was $60 \%$ in those with HIV so it was approved by the FDA in 2020 for Kaposi treatment in HIV patients following treatment failure..$^{28}$ In the cases of failure attended in our hospital, it was decided to change to the drug that was not previously administered where there is no documented progression after it regardless of the agent used.

Long-term follow-up is based on the fact that the origin of Kaposi's sarcoma, i.e. HHV8, persists even with chemotherapy and/or antiretrovirals, so the risk of recurrence persists even after complete remission. This risk depends on the immune function, however persistence or relapses have been documented even with CD4 in normal ranges so the objective of treatment is to improve the quality of life of the patient, remission of symptoms and avoid organ damage. Cancer follow-up is done every 6 to 12 months in patients with undetectable viral load, normal CD4 and stable lesions for 2 or more years. ${ }^{12}$ In our reported cases, relapses have not been documented until their last follow-up appointment, which for an average follow-up period of 30 months speaks to a good response so it is advisable to carry out a longer follow-up to define the disease-free period that our population would have (Figure 1)



Figure I Patients Distribution.

\section{Conclusions}

Kaposi's sarcoma is a disease present in the population of patients with HIV-AIDS, so it is important to continue studying and monitoring the therapeutic options currently available. It is necessary to integrate prospective cohorts that demonstrate the efficacy of treatment with the disease-free period that occurred in this population.

The experience of hospitals with HIV and oncology clinics shows the follow-up of this population with the use of systemic therapies and their adverse effects. It is urgent that clinical interventions be carried out with therapeutic trials since the available evidence dates from periods of more than 10 years ago to be able to offer the best therapeutic options for patients with HIV-AIDS with the presence of Kaposi sarcoma.

\section{Acknowledgments}

None. 


\section{Funding}

None.

\section{Conflicts of interest}

The authors have no conflicts of interest to declare.

\section{References}

1. HIV Gov. US Statistics. 2018.

2. CENSIDA, Secretary of Health. Epidemiological Surveillance of HIV/ AIDS cases in Mexico National Registry of AIDS Cases Update to the 2 second . Quarter of 2019. Ministry of Health. 2019;23.

3. National Center for the Prevention and Control of HIV and AIDS. Epidemiology National Registry of HIV and AIDS Cases. 2020.

4. Niederhuber JE, Armitage JO, Doroshow JH, et al. Abeloff's Clinical Oncology. 6th ed. United States: Elsevier. 2020.

5. Robbins HA, Pfeiffer RM, Shiels MS, et al. Excess cancers among HIVinfected people in the United States. Journal of the National Cancer Institute. 2015;107(4):1-8.

6. International Agency for Research on Cancer Globocan 2020. Kaposi sarcoma. 2020

7. Etemad SA, Dewan AK. Kaposi Sarcoma Updates. Dermatologic Clinics. 2019;37(4):505-517.

8. Cesarman E, Damania B, Krown SE, et al. Kaposi sarcoma. Nature Reviews Disease Primers. 2019;5(1).

9. Krown, Susan E. Metroka CWJC. Kaposi 's Sarcoma in the Acquired Immune Deficiency Syndrome: A Proposal for Uniform Evaluation, Response and Staging Criteria. Journal of Clinical Oncology. 1989;7(9):1201-1207.

10. Nasti G, Talamini R, Antinori A, et al. AIDS-related Kaposi's sarcoma: Evaluation of potential new prognostic factors and assessment of the AIDS Clinical Trial Group staging system in the Haart era - The Italian Cooperative Group on AIDS and tumors and the Italian cohort of naïve patients from . Journal of Clinical Oncology. 2003;21(15):2876-2882.

11. Beatrous S v, Grisoli SB, Riahi RR, et al. Cutaneous HIV-associated kaposi sarcoma: A potential setting for management by clinical observation. Dermatology Online Journal. 2017;23(6):0-6.

12. Deborah Freedman-Cass N, Hollinger L, Reid E, et al. Kaposi Sarcoma National Comprehensive Cancer Network. 2021.

13. Armstrong AW, Lam KH, Chase EP. Epidemiology of classic and AIDS-related Kaposi's sarcoma in the USA: Incidence, survival, geographical distribution from 1975 to 2005. Epidemiology and Infection. 2013;141(1):200-206.

14. Cancer Editorial Board. Sarcoma Kaposi Statistics. 2020.
15. Volkow P, Cesarman-Maus G, Garciadiego-Fossas P, et al. Clinical characteristics, predictors of immune reconstitution inflammatory syndrome and long-term prognosis in patients with Kaposi sarcoma. AIDS Res Ther. 2017;14(1):1-9.

16. Fernández-Sánchez M, Iglesias MC, Ablanedo-Terrazas Y, et al. Steroids are a risk factor for Kaposi's sarcoma-immune reconstitution inflammatory syndrome and mortality in HIV infection. Aids. 2016;30(6):909-914.

17. Bodsworth NJ, Bloch M, Bower M, et al. Phase III Vehicle-Controlled, Multi-Centered Study of Topical Alitretinoin Gel 0.1\% in Cutaneous AIDS-Related Kaposi's Sarcoma. Am J Clin Dermatol. 2001;2(2):77-87.

18. Célestin Schartz NE, Chevret S, Paz C, et al. Imiquimod 5\% cream for treatment of HIV-negative Kaposi's sarcoma skin lesions: A phase I to II, open-label trial in 17 patients. J Am Acad Dermatol. 2008;58(4):585-591.

19. Pria AD, Pinato DJ, Bracchi M, et al. Recent advances in hiv-associated kaposi sarcoma. Vol. 8, F1000Research. F1000 Research Ltd; 2019.

20. Suneja G. New NCCN Guidelines: Cancer Management in People Living With HIV. J Natl Compr Canc Netw. 2018;16(5S):597-599.

21. Northfelt DW, Dezube BJ, Thommes JA, et al. Pegylated-liposomal doxorubicin versus doxorubicin, bleomycin, and vincristine in the treatment of AIDS-related Kaposi's sarcoma: Results of a randomized phase III clinical trial. Journal of Clinical Oncology. 1998;16(7):24452451 .

22. Stewart S, Jablonowski H, Goebel FD, et al. Randomized comparative trial of pegylated liposomal doxorubicin versus bleomycin and vincristine in the treatment of AIDS-related Kaposi's sarcoma. Journal of Clinical Oncology. 1998;16(2):683-691.

23. Cianfrocca M, Lee S, Roenn J von, et al. Randomized Trial of Paclitaxel versus Pegylated Liposomal Doxorubicin for Advanced Human Immunodeficiency Virus-associated Kaposi's Sarcoma: Evidence for Symptom Palliation from Chemotherapy. Cancer. 2010;116(16):39693977.

24. Gbabe O, Okwundu C, Dedicoat $\mathrm{M}$, et al. Treatment of severe or progressive Kaposi', s sarcoma in HIV- infected adults. Cochrane Database Syst Rev. 2014;(9).

25. Northfelt DW, Dezube BJ, Thommes JA, et al. Efficacy of pegylatedliposomal doxorubicin in the treatment of AIDS- related Kaposi's sarcoma after failure of standard chemotherapy. Journal of Clinical Oncology. 1997;15(2):653-659.

26. Stebbing J, Wildfire A, Portsmouth S, et al. Paclitaxel for anthracyclineresistant AIDS-related Kaposi's sarcoma: Clinical and angiogenic correlations. Annals of Oncology. 2003;14(11):1660-1666.

27. Polizzotto MN, Uldrick TS, Wyvill KM, et al. Pomalidomide for symptomatic Kaposi's sarcoma in people with and without HIV infection: A phase I/II study. Journal of Clinical Oncology. 2016;34(34):4125-4131.

28. US Food and Drug Administration. FDA grants accelerated approval to pomalidomide for Kaposi sarcoma. 2020. 